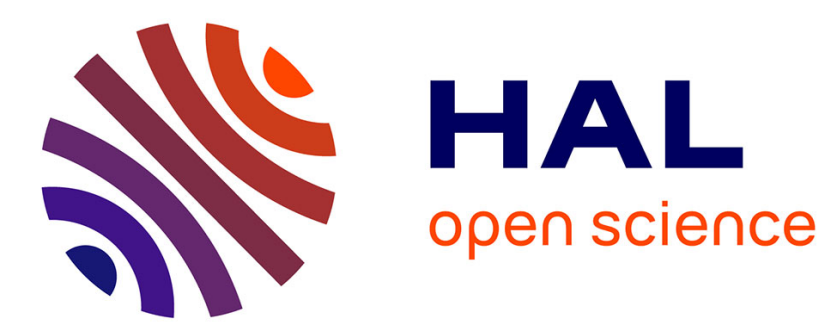

\title{
CdSe Nanoplatelets: Living Polymers
}

Benjamin Abecassis, Santanu Jana, Patrick Davidson

\section{To cite this version:}

Benjamin Abecassis, Santanu Jana, Patrick Davidson. CdSe Nanoplatelets: Living Polymers. Angewandte Chemie, 2016, 128 (32), pp.9517-9520. 10.1002/ange.201603880 . hal-02995333

\section{HAL Id: hal-02995333 \\ https://hal.science/hal-02995333}

Submitted on 9 Nov 2020

HAL is a multi-disciplinary open access archive for the deposit and dissemination of scientific research documents, whether they are published or not. The documents may come from teaching and research institutions in France or abroad, or from public or private research centers.
L'archive ouverte pluridisciplinaire HAL, est destinée au dépôt et à la diffusion de documents scientifiques de niveau recherche, publiés ou non, émanant des établissements d'enseignement et de recherche français ou étrangers, des laboratoires publics ou privés. 


\title{
CdSe Nanoplatelets Living Polymers
}

\author{
Santanu Jana, ${ }^{[\mathrm{a}]}$ Patrick Davidson ${ }^{[\mathrm{a}]}$ and Benjamin Abécassis ${ }^{*[\mathrm{a}]}$ \\ [a] Laboratoire de Physique des Solides, Université Paris Saclay, CNRS, 91400 Orsay
}

\begin{abstract}
Colloidal CdSe nanoplatelets are considered to be excellent candidates for many applications in nanotechnology. One of the current challenges is to self-assemble these colloidal quantum wells into large ordered structures to control their collective optical properties. We describe a simple and robust procedure to achieve controlled face-to-face self-assembly of CdSe nanoplatelets into micron-long polymer-like threads made of up to $\sim 1000$ particles. These structures are formed by addition of oleic acid to a stable colloidal dispersion of platelets, followed by slow drying and re-dispersion. We could control the average length of the CdSe nanoplatelet threads by varying the amount of added oleic acid. These 1-dimensional structures are flexible and feature a "living polymer" character since threads of a given length can be further grown through the addition of supplementary nanoplatelets at their reactive ends.
\end{abstract}

The organization of colloidal assemblies of nanocrystals (NC) over large areas and volumes is of great interest in nanotechnology because it is required for elaborating artificial solids and functional devices. ${ }^{[1-3]} \mathrm{NC}$ superlattices have been proposed for a wide range of optoelectronics, thermoelectric and chemical sensing applications. ${ }^{[4-7]}$ In the field of semiconducting NC, nanoplatelets (NPL), also coined "colloidal quantum wells", have recently received much attention due to their outstanding optical properties such as tunable, very sharp, emission wavelength, carrier recombination faster than that of quantum dots and rods, and low-threshold lasing properties. ${ }^{[8,9]}$ These features make NPL ideal
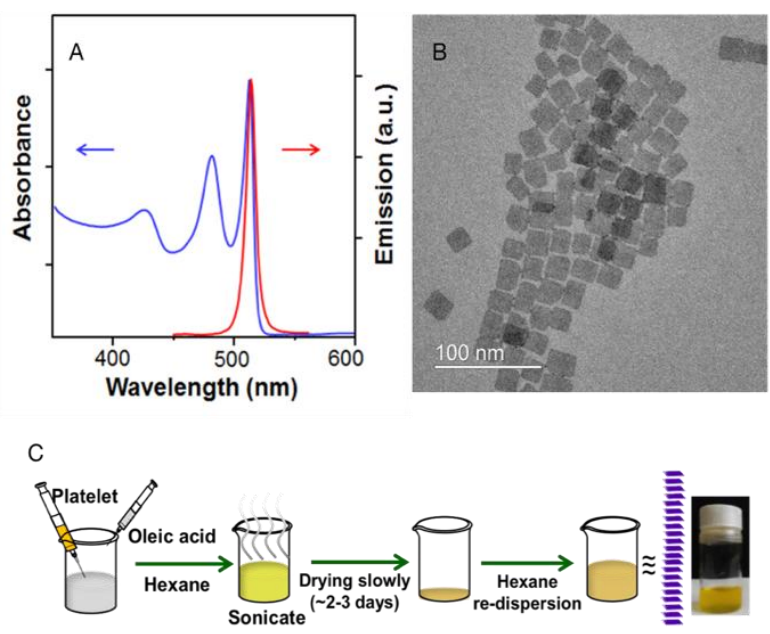

have been reported recently. ${ }^{[21-23]}$ The most common geometry is (possibly branched) chai ns that are called "plasmonic polymers" since they give rise to a shift in the plasmon resonance of the nanocrystals. ${ }^{[21,24]}$ The spontaneous assembly of particles into chains was achieved by chemical cross-linking, physical attraction between ligands, or oriented attachment of nanocrystals. ${ }^{[25-28]}$ The aggregation number of these polymeric assemblies is usually comprised between 5 and 20 . However, there is not to date any such report of polymeric 1-D assembly for colloidal quantum wells.

Here, we demonstrate a simple strategy to induce the self-assembly of CdSe NPL into micron-long threads by adding small amounts of oleic acid (OA) to a NPL dispersion, followed by slow drying. The concentration of added OA is a critical factor that controls the assembly and the length of the threads. Furthermore, the threads can be used as seeds for further growth like in living polymers where monomers can be added to reactive ends of an already polymerized chain.

4-monolayer (ML) CdSe NPL were synthesized by slightly modifying a previously reported synthesis ${ }^{[15]}$ (see experimental section for details). An excess of OA was used at the end of the synthesis so that all faces of the NPL are fully covered by ligands. After thorough purification through repeated precipitation/redispersion cycles, the NPL were dispersed in hexane. The absorption and emission spectra (Figure 1.a) show that only one 4ML population was found in solution. Transmission electron microscopy (TEM) images (Figure 1.b and S1) of the platelets showed that the $4 \mathrm{ML}$ NPL are square with 18 nm edges. 

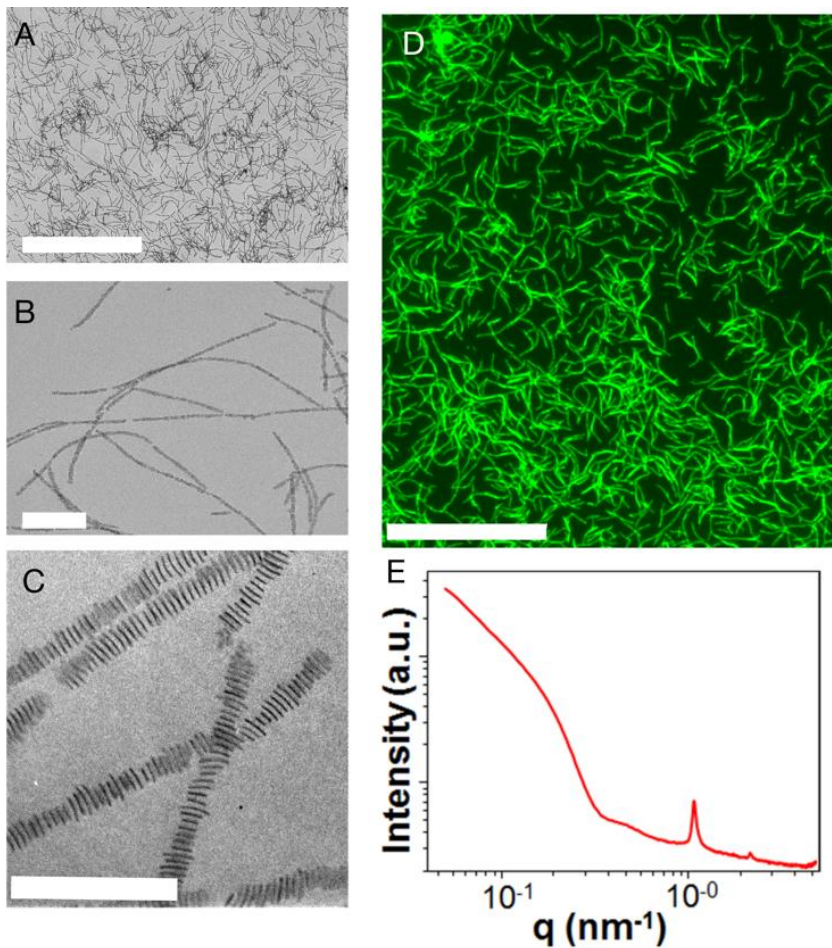

Figure 2: $(A)$ and $(B)$ : lower and higher magnification TEM images of threads of $4 \mathrm{ML}$ square platelets. (C) High-resolution TEM image of the threads showing the face to face stacking of CdSe platelets. (D) Fluorescence microscopy images of the threads deposited from solution on a cover slip. (E) Small angle X-ray scattering curve of the thread dispersion. Scale bars: $5 \mu \mathrm{m}(\mathrm{A}), 200 \mathrm{~nm}(\mathrm{~B}), 20$ $\mathrm{nm}(\mathrm{C}), 20 \mu \mathrm{m}(\mathrm{D})$ reported. ${ }^{[18]}$ Interestingly, the fluorescence of CdSe NPL is not quenched by their self-assembly and the threads on a glass substrate are easily detected by fluorescence microscopy (Figure 2d). Although the lateral spatial resolution of the confocal microscope is of the order of $200 \mathrm{~nm}$, we can clearly see the elongated character of the threads using this technique. Another interesting feature, shown by both the electron and fluorescence microscopies, is the absence of individual NPL in solution besides the threads. All the platelets take part in the self-assembly process and none are present as "monomers" in solution.

Due to their large aspect ratio, these threads are not completely straight and appear somewhat flexible. Furthermore, in solution, we observed by fluorescence microscopy that the threads occasionally break and reform (see video in supplementary information and figure S3). The threads therefore share this similarity with giant wormlike micelles observed in some surfactant ${ }^{[29]}$ or block copolymers ${ }^{[30]}$ solutions. A noticeable difference being that, in the case of surfactant micelles, monomers (i.e. single surfactant molecules) are continuously exchanged between the solution and the aggregates whereas here, relatively large parts of the threads detach and re-attach dynamically. This is visible on figure S3 where a thread fragment $\sim 250 \mathrm{~nm}$ long (and hence made of $\sim 50 \mathrm{NP}$ ) separates from a large thread and then re-merges with it after drifting in solution for a few seconds. This however could be due to flows within the sample cell because the NPL threads are large objects formed by non-covalent self-assembly and they could therefore be very much affected by hydrodynamic stresses.

By tuning the amount of added OA, it is possible to control precisely the mean thread length (Figure 3). Without any further

addition of $\mathrm{OA}$, single platelets and very short platelet stacks are found in suspension. For an $\mathrm{OA}$ concentration of $6 \mathrm{mM}$, the CdSe NPL stack and form small threads of length 100-200 nm. The length of the threads further increases up to a mean length of $1.4 \mu \mathrm{m}$ for $[\mathrm{OA}]=48 \mathrm{mM}$ (Figure 3). This size increase is also clearly observed by fluorescence confocal microscopy although the threads of smallest size only appear as small bright spots since they are smaller than the lateral resolution of the microscope (Figure $3 \mathrm{a}-\mathrm{d}$ ). It should be noted that, for all values of OA concentrations, the 
polydispersity index remained low $(\mathrm{PDI}=1.05 \pm 0.03$ ). After reaching a maximum for an $\mathrm{OA}$ concentration of $48 \mathrm{mM}$, further ligand addition resulted in the precipitation of the colloid. Whatever their length, the width of the CdSe threads always remained equal to the edge length of the platelets.

We now turn to the mechanism by which self-assembly occurs and we try to propose a physical explanation to the influence of OA concentration on the thread length. We merely consider the simple case of 1-dimensional self-assembly of NPL in threads under the influence of pairwise attractive interactions between platelets at contact and facing each other. There are two types of attractive potentials whose intensities can be larger than kT (where k is the Boltzmann constant and $\mathrm{T}$ is the temperature): van der Waals and depletion. Van der Waals attractions are always present and destabilize colloidal suspensions of platelets on a time scale ranging from minutes to days, depending on NPL
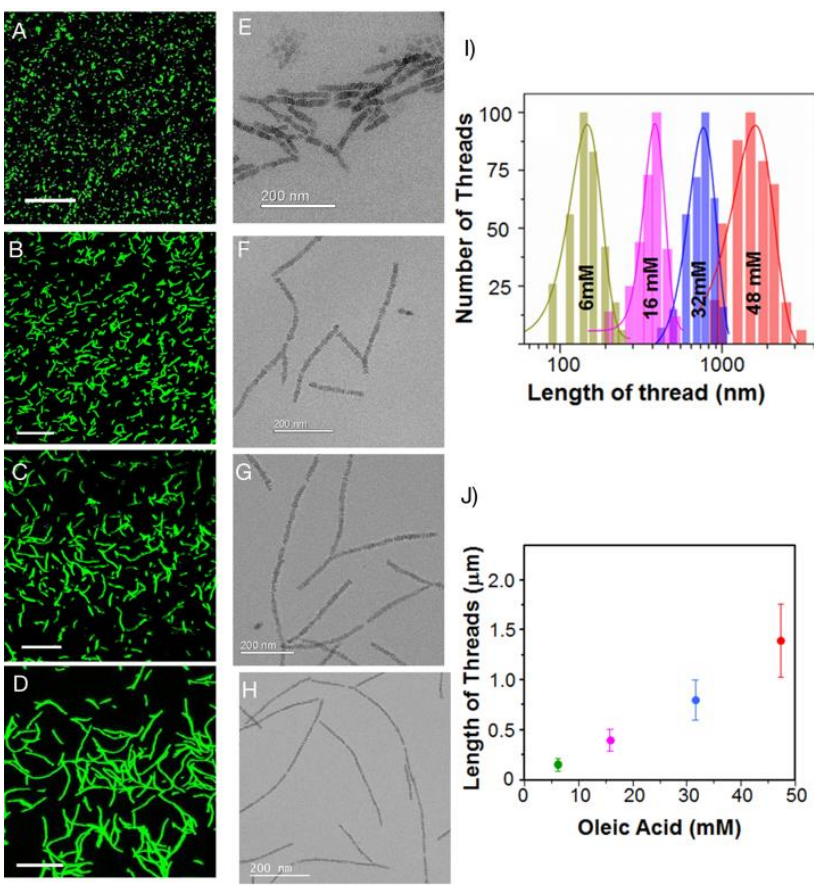

J)

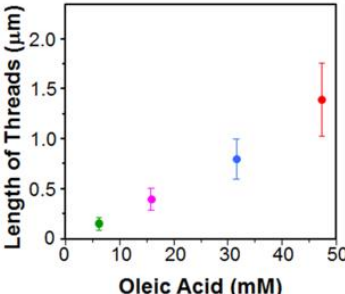

Figure 3. Evolution of threads of square CdSe platelets using different concentrations of added OA. (A-D) Confocal Fluorescence microscopy images of the threads obtained with different concentrations of $O A, 6 \mathrm{mM}$, $16 \mathrm{mM}, 32 \mathrm{mM}$, and $48 \mathrm{mM}$, respectively. (scale bars: $5 \mu \mathrm{m})$. (E-H) Corresponding TEM images of CdSe threads. (scale bars: $200 \mathrm{~nm}$ ) (I) Length polydispersity distributions of CdSe NP threads for different concentrations of added OA. $(\mathrm{J})$ Dependence of the thread average length on the concentration of $\mathrm{OA}$ added to the platelet solution in hexane. concentration ${ }^{[31]}$ but this weak $(\sim 2 \mathrm{kT})$ interaction does not explain the dependence of thread length on OA concentration. On the other hand, the depletion interaction exerted by free oleic acid molecules on the NPL is a much better candidate in this respect. Even though the size of OA molecules is small $(\sim 2 \mathrm{~nm})$, their concentration can reach high enough values to induce a strong attractive potential on the NPL, of the order of 10 $\mathrm{kT}$ at the beginning of the drying process. Moreover, the intensity of these attractions depends linearly on the OA concentration ${ }^{[32]}$, which explains the thread length increase with increasing $O A$ concentration.

In the field of macromolecular synthesis, reactive macromolecules that can grow when supplementary monomers are added in solution can be produced either by the mechanism of "step-growth" polymerization or by that of "living" polymerization. The latter type of polymerization differs from the former by the good control of the degree of polymerization, with a low polydispersity index, by a linear dependence of the average molecular weight on monomer conversion, and by the fact that further monomer addition only results in chain propagation, with no formation of new polymer chains. ${ }^{[3-37]}$. Since the chain ends are reactive, new monomers attach to existing chains and the mean chain length (polymerization degree) increases while the number of macromolecules remains constant. In order to investigate whether the CdSe NPL threads feature this property, we prepared "small" $(\sim 300 \mathrm{~nm})$ threads, re-dispersed them in a solution of free platelets and slowly evaporated the solvent (see supplementary information for experimental details). If the new NPLs only attach to the existing threads and do not form new threads, the contour length will increase by an amount proportional to $n_{N P L} / N$ where $n_{N P L}$ is the concentration of NPL added and $N$ is the initial number of threads in solution. Hence, if we plot the contour length (propotionnal to the number of NPL in a thread) as a function of the quantity of added NPLs we should obtain a straight line. This is actually what is observed (Figure 4); the threads grew to an extent simply predictable from the amount of added NPL. Interestingly, free NPL attach to both ends of the existing threads and do not form new chains. Finally, since one of the most interesting application of living polymerization is the synthesis of block-copolymers, we tried the synthesize ABA type triblock copolymers through the addition of $5 \mathrm{ML} N \mathrm{NPL}$ to already formed $4 \mathrm{ML}$ threads. Taking advantage of the different emission wavelengths between the NPLs of different thicknesses, we could localize $4 \mathrm{ML}$ and $5 \mathrm{ML}$ independently using the confocal microscope. Figure S4 shows that 4 and 5ML NPLs are colocalized on the same threads and that $5 \mathrm{ML}$, added after the formation of $4 \mathrm{ML}$ threads, are more likely situated at the extremities of the threads. Together with the low polydispersity index and the re-growth of $4 \mathrm{ML}$ threads, this is another evidence for a living polymerization mechanism in this system. 


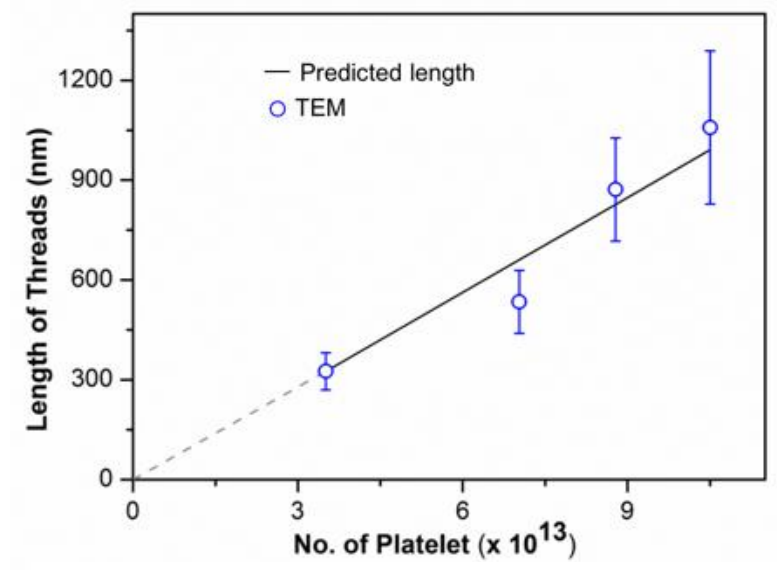

Figure 4: Mean length of threads as a function of added NPL number for re-growth of initial threads.

In conclusion, we have developed a simple method to self-assemble CdSe nanoplatelets into long flexible threads through slow evaporation of colloidal solutions. These threads are composed of hundreds to thousands of individual platelets. We can control the average number of platelets per threads with the concentration of added OA or through subsequent regrowth of existing threads. We expect this control over their self-assembly to yield interesting developments in the study of emerging properties in ensembles of NPL. In principle, the simple procedure described here could also be potentially generalized to other systems of 2-dimensional colloidal nanocrystals.

\section{Experimental Section}

Chemicals: Cadmium acetate dihydrate $\left(\mathrm{Cd}(\mathrm{OAc})_{2} \cdot 2 \mathrm{H}_{2} \mathrm{O}\right)$, myristic acid, technical grade 1-octadecene (ODE), oleic acid $(\mathrm{OA})$ and selenium in powder were purchased from Sigma-Aldrich. Ethanol and hexane were purchased from SDS Carlo-Erba. The preparation of cadmium myristate was performed as reported in literature.

Synthesis and purification of nanoplatelets: For a typical synthesis, $340 \mathrm{mg}$ of cadmium myristate, $27 \mathrm{mg}$ of selenium powder and 25 $\mathrm{mL}$ of octadecene were introduced into a three-neck round bottom $50 \mathrm{~mL}$ flask, equipped with a septum, a temperature controller and a condenser, and were kept under vacuum for 30 minutes. Afterwards, the flask was purged with argon and the temperature was set to $230{ }^{\circ} \mathrm{C}$. At $180-190^{\circ} \mathrm{C}$, the selenium started to dissolve and the solution turned clear yellow. When the temperature reached $205^{\circ} \mathrm{C}$, the septum was withdrawn and $160 \mathrm{mg}$ of cadmium acetate was swiftly added into the flask. After the temperature reached $240{ }^{\circ} \mathrm{C}$, the reaction continued for 12-15 minutes, $1 \mathrm{~mL}$ of oleic acid was injected at the end and the flask was immediately cooled down to room temperature. At this stage, the reaction product was a mixture of $3 \mathrm{ML} N P L, 4 M L N P L$ and quantum dots in solution. The $4 \mathrm{ML} N P L$ were collected using size-selective precipitation by addition of ethanol and redispersion in hexane. This washing procedure was repeated 3 times and the yellow colored platelets were dispersed in hexane to prepare a stock solution for further self-assembly.

Self-assembly of nanoplatelets: $1 \mathrm{ml}$ of the NPL stock solution $(4 \mathrm{mg} / \mathrm{ml}$ ), the required amount of oleic acid (for example $15 \mu \mathrm{l} / \mathrm{ml}$ for long threads) and $4 \mathrm{ml}$ of hexane were mixed together in a $15 \mathrm{ml}$ vial and sonicated for $30 \mathrm{~min}$ at room temperature to obtain a transparent solution. Then, the vial was kept with cap slightly open at room temperature to slowly evaporate hexane. Complete evaporation of hexane took about three days. After complete evaporation, the deposit was re-dispersed in $3 \mathrm{ml}$ of hexane by shaking. The solution looked slightly turbid and remained stable upon further dilution with hexane.

\section{Acknowledgements}

This work is supported by "Investissements d'Avenir" LabEx PALM (ANR-10-LABX-0039-PALM). We acknowledge SOLEIL for provision of synchrotron radiation facilities and we would like to thank Javier Perez and for assistance in using beamline SWING; we also acknowledge Doru Constantin and Rik Wensink for helpful discussions.

Keywords: nanoplatelets $•$ self-assembly $\bullet$ living polymer $\bullet$ quantum dots $\bullet$ nanostructures

[1] S. C. Glotzer, M. J. Solomon, Nat. Mater. 2007, 6, 557-562.

[2] Z. Nie, A. Petukhova, E. Kumacheva, Nat Nanotechnol 2010, 5, 15-25.

[3] D. V. Talapin, J.-S. Lee, M. V. Kovalenko, E. V. Shevchenko, Chem Rev 2010, 110, 389-458.

[4] S. Coe, W.-K. Woo, M. Bawendi, V. Bulović, Nature 2002, 420, 800-803.

[5] B. A. Ridley, B. Nivi, J. M. Jacobson, Science 1999, 286, 746-749.

[6] D. V. Talapin, C. B. Murray, Science 2005, 310, 86-89.

[7] C. Hu, K. Lin, X. Wang, S. Liu, J. Yi, Y. Tian, B. Wu, G. Chen, H. Yang, Y. Dai, et al., J. Am. Chem. Soc. 2014, 136, 12856-12859.

[8] S. Ithurria, B. Dubertret, J. Am. Chem. Soc. 2008, 130, 16504-16505.

[9] E. Lhuillier, S. Pedetti, S. Ithurria, B. Nadal, H. Heuclin, B. Dubertret, Acc Chem Res 2015, 48, $22-30$.

[10] Z. Chen, B. Nadal, B. Mahler, H. Aubin, B. Dubertret, Adv Funct Mater 2014, 24, 295-302.

[11] E. Lhuillier, A. Robin, S. Ithurria, H. Aubin, B. Dubertret, Nano Lett. 2014, 14, 2715-2719.

[12] M. Lorenzon, S. Christodoulou, G. Vaccaro, J. Pedrini, F. Meinardi, I. Moreels, S. Brovelli, Nat. Commun. 2015, 6, DOI 10.1038/ncomms7434.

[13] A. E. Saunders, A. Ghezelbash, D.-M. Smilgies, , Michael B. Sigman, B. A. Korgel, Nano Lett. 2006, 6, $2959-2963$.

[14] Z. Huo, C.-K. Tsung, W. Huang, M. Fardy, R. Yan, X. Zhang, Y. Li, P. Yang, Nano Lett. 2009, 9, 1260-1264.

[15] B. Abecassis, M. D. Tessier, P. Davidson, B. Dubertret, Nano Lett. 2014, 14, 710-715.

[16] C. E. Rowland, I. Fedin, H. Zhang, S. K. Gray, A. O. Govorov, D. V. Talapin, R. D. Schaller, Nat. Mater. 2015, 14, 
484-489.

[17] I. Moreels, Nat. Mater. 2015, 14, 464-465.

[18] M. D. Tessier, L. Biadala, C. Bouet, S. Ithurria, B. Abecassis, B. Dubertret, ACS Nano 2013, 7, 3332-3340.

[19] B. Guzelturk, O. Erdem, M. Olutas, Y. Kelestemur, H. V. Demir, ACS Nano 2014, 8, 12524-12533.

[20] B. Guzelturk, M. Olutas, S. Delikanli, Y. Kelestemur, O. Erdem, H. V. Demir, Nanoscale 2015, 7, 2545-2551.

[21] K. Liu, Z. Nie, N. Zhao, W. Li, M. Rubinstein, E. Kumacheva, Science 2010, 329, 197-200.

[22] K. Liu, A. Lukach, K. Sugikawa, S. Chung, J. Vickery, H. Therien-Aubin, B. Yang, M. Rubinstein, E. Kumacheva, Angew. Chem. Int. Ed. 2014, 53, 2648-2653.

[23] H. Wang, L. Chen, X. Shen, L. Zhu, J. He, H. Chen, Angew. Chem. Int. Ed. 2012, 51, 8021-8025.

[24] S. J. Barrow, A. M. Funston, D. E. Gómez, T. J. Davis, P. Mulvaney, Nano Lett. 2011, 11, 4180-4187.

[25] J. Wang, H. Xia, Y. Zhang, H. Lu, R. Kamat, A. V. Dobrynin, J. Cheng, Y. Lin, J. Am. Chem. Soc. 2013, 135,

$11417-11420$.

[26] Z. Nie, D. Fava, E. Kumacheva, S. Zou, G. C. Walker, M. Rubinstein, Nat. Mater. 2007, 6, 609-614.

[27] K. K. Caswell, J. N. Wilson, U. H. F. Bunz, C. J. Murphy, J. Am. Chem. Soc. 2003, 125, 13914-13915.

[28] S. Shanbhag, Z. Tang, N. A. Kotov, ACS Nano 2007, 1, 126-132.

[29] A. Khatory, F. Kern, F. Lequeux, J. Appell, G. Porte, N. Morie, A. Ott, W. Urbach, Langmuir 1993, 9, $933-939$.

[30] Y.-Y. Won, H. T. Davis, F. S. Bates, Science 1999, 283, 960-963.

[31] S. Jana, T. N. T. Phan, C. Bouet, M. D. Tessier, P. Davidson, B. Dubertret, B. Abécassis, Langmuir 2015, 31, 10532-10539.

[32] H. N. W. Lekkerkerker, R. Tuinier, Colloids and the Depletion Interaction, Springer Science \& Business Media, 2011.

[33] O. W. Webster, Science 1991, 251, 887-893.

[34] W. A. Braunecker, K. Matyjaszewski, Prog. Polym. Sci. 2007, 32, 93-146.

[35] J.-S. Wang, K. Matyjaszewski, J. Am. Chem. Soc. 1995, 117, 5614-5615.

[36] S. C. Greer, Annu. Rev. Phys. Chem. 2002, 53, 173-200.

[37]X. Wang, G. Guerin, H. Wang, Y. Wang, I. Manners, M. A. Winnik, Science 2007, 317, 644-647. 